early RA, and quantify the extent of subclinical inflammation in these patients.

Methods: DMARD-naïve early RA patients included in the treat-to-target ARCTIC trial were followed by a strict tight control regime aiming for DAS remission and no swollen joints, with an additional target of ultrasound remission in half of the patients.(3) Examination of all patients included 44SJC, Ritchie articular index (RAI), laboratory tests, patient reported outcomes included physical function (PROMIS), ultrasound (US) of 32 joints and magnetic resonance imaging (MRI) of the dominant hand and wrist (scored according to RAMRIS). Patients with complete clinical data at the 2-year follow-up visit were included in the current analyses. We assessed the proportion of patients fulfilling ACR/EULAR Boolean remission (based on 44 joints) and the proportion of patients fulfilling three out of four remission criteria, and in such cases, which were the limiting factors. We compared physical function and imaging inflammation (assessed by US power Doppler score, US grey scale score, MRI synovitis and bone marrow edema) in patients reaching complete ACR/ EULAR Boolean remission to patients not reaching ACR/EULAR Boolean remission due to the most often limiting factors. Chi2 test and Wilcoxon rank sum test were used for the comparisons.

Results: Of the 203 patients included, 62\% were females, mean (SD) age was 52 (13) years, and $81 \%$ were ACPA positive. ACR/EULAR Boolean remission was achieved by 112 of 203 patients after 24 months $(55 \%)$, while $49(24 \%)$ fulfilled three of the four remission criteria. Among these 49 patients, the major limiting factor for not reaching remission was PGA $(n=29,59 \%)$, with tender joints as the second most common limiting factor $(n=11,22 \%)$ (Figure). In patients not achieving remission due to PGA, the median [IQR] PGA value was 3.1 [2, 4.4]. Subclinical inflammation measured by ultrasound and MRI was not significantly different for patients in ACR/EULAR Boolean remission compared to patients not fulfilling these criteria due to PGA and/or tender joints (Table), but the latter reported more subjective symptoms such as fatigue and impaired physical function.

Figure: The proportion of patients with failure to fulfill the ACR/EULAR Boolean remission criteria due to one of the four components; tender joint count $>1$ or $\mathrm{SJC} 44>1$ or $\mathrm{CRP}>1 \mathrm{mg} / \mathrm{dl}$ or PGA $>1$. $\mathrm{N}=49$.

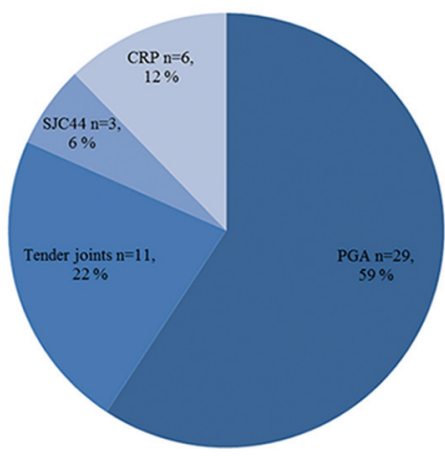

\begin{tabular}{|c|c|c|c|}
\hline & & SIC $44<1+C R P<1$ & \\
\hline & ACR/EULAR Boolean & $+\mathrm{PGA}>1$ and $/$ or tender & P-yalue for difference \\
\hline Age & $53.6[41.1 .63 .4]$ & $53.3[43,61.2]$ & 0.77 \\
\hline Female, $\mathrm{n}(\%)$ & $65(58.0)$ & $44(72.1)$ & 0.07 \\
\hline ACPA, n (\%) & $88(78.6)$ & $53(86.9)$ & 0.18 \\
\hline $\mathrm{RF}, \mathrm{n}(\%)$ & $74(66.1)$ & $43(70.5)$ & 0.55 \\
\hline $\begin{array}{l}\text { PROMIS physical } \\
\text { function t-score }\end{array}$ & $62.5[50.0,62.5]$ & $45.3[40.2,50.0]$ & $<0.001$ \\
\hline Fatigue VAS $(0-100)$ & $3.5[1.0,12.0]$ & $34.0[17.0,50.0]$ & $<0.001$ \\
\hline Physician's global (0-10) & $0.2[0.1,0.8]$ & $0.8[0.4,1.2]$ & $<0.001$ \\
\hline $\begin{array}{l}\text { Ultrasound power } \\
\text { Doppler score }(0-96)\end{array}$ & $0.0[0.0,0.0]$ & $0.0[0.0,0.0]$ & 0.75 \\
\hline $\begin{array}{l}\text { Ultrasound Grey Scale } \\
\text { score (0-96) }\end{array}$ & $3.0[1.0,5.5]$ & $3.0[0.0,6.0]$ & 0.69 \\
\hline $\begin{array}{l}\text { MRI RAMRIS synovitis } \\
(0-39)\end{array}$ & $5.4[3.7,7.1]$ & $5.0[3.8,6.2]$ & 0.68 \\
\hline $\begin{array}{l}\text { MRI RAMIRIS bone } \\
\text { marrow edema }(0-105)\end{array}$ & $1.0[0.0,3.2]$ & $1.8[0.0,3.2]$ & 0.21 \\
\hline
\end{tabular}

Conclusion: PGA and tender joints are the variables most often limiting patients from achieving ACR/EULAR Boolean remission, also in a treat-totarget setting with high remission rates. The level of subclinical inflammation is not elevated in these patients compared to patients in ACR/ EULAR Boolean remission. Further research is still needed to assess which clinical remission criterion is best suited to guide treatment.
[2] Studenic P, et al. ARD. 2012;71(10).

[3] Haavardsholm EA, et al. BMJ. 2016;354.

Disclosure of Interests: nina sundlisater: None declared, Anna-Birgitte Aga Consultant for: UCB, AbbVie, and Pfizer, Paid instructor for: UCB, Ulf Sundin: None declared, Hilde Berner Hammer Grant/research support from: AbbVie, Pfizer and Roche, Paid instructor for: AbbVie, Pfizer, UCB Novartis, Roche, Speakers bureau: AbbVie, Pfizer, UCB, Novartis, Roche, Till Uhlig Consultant for: Grünenthal, Novartis, Speakers bureau: Grünenthal, Novartis, Tore K. Kvien Grant/research support from: AbbVie, BMS, MSD, Pfizer, Roche and UCB., Consultant for: AbbVie, Biogen, BMS Boehringer Ingelheim, Celgene, Celltrion, Eli Lilly, Hospira, Merck-Serono, MSD, Novartis, Oktal, Orion Pharma, Pfizer, Roche, Sandoz, Sanofi, Mylan and UCB, Speakers bureau: AbbVie, Biogen, BMS, Boehringer Ingelheim, Celgene, Celltrion, Eli Lilly, Hospira, Merck-Serono, MSD, Novartis, Oktal, Orion Pharma, Pfizer, Roche, Sandoz, Sanofi and UCB, Espen Haavardsholm Grant/research support from: Pfizer, UCB, Roche, MSD, and AbbVie, Consultant for: Pfizer, Paid instructor for: Pfizer Speakers bureau: Pfizer, UCB, Roche, and AbbVie, Siri Lillegraven: None declared

DOI: 10.1136/annrheumdis-2019-eular.3212

\section{SAT0114 INCREASED PREVALENCE AND SEVERITY OF CORONARY ARTERY DISEASE IN PATIENTS WITH CHEST PAIN AND SEROPOSITIVE RHEUMATOID ARTHRITIS: AN ANALYSIS FROM A LARGE-SCALE POPULATION COHORT REFERRED FOR CARDIAC COMPUTED TOMOGRAPHY}

Andreas Bugge Tinggaard ${ }^{1}$, Annette de Thurah ${ }^{2}$, Ina Trolle Andersen ${ }^{3}$, Anders Hammerich Riis ${ }^{3}$, Josephine Therkildsen ${ }^{2}$, Simon Winther ${ }^{4}$, Ellen-

Margrethe Hauge ${ }^{2}$, Morten Böttcher ${ }^{1} .{ }^{1}$ Hospital Unit West, Herning, Department of Cardiology, Herning, Denmark; ${ }^{2}$ Aarhus University Hospital, Department of Rheumatology, Aarhus, Denmark; ${ }^{3}$ Aarhus University Hospital, Department of Clinical Epidemiology, Aarhus, Denmark; ${ }^{4}$ Aarhus University Hospital, Department of Cardiology, Aarhus, Denmark

Background: Inflammation plays a central role in the development of atherosclerosis and inflammatory disease might promote progression of CAD

Objectives: To examine the impact of the most frequent systemic inflam matory disease, rheumatoid arthritis (RA), on the prevalence and severity of coronary artery disease (CAD) in patients referred for rule out of CAD by cardiac computed tomography (CCT).

Methods: In total, 39,534 patients from a mandatory national CCT database were included. Patients with a validated RA diagnosis were subgrouped based on serology, treatment with biological disease-modifying anti-rheumatic drugs (DMARDs), and the need for flare treatment with intraarticular and intramuskular glucocorticoid injections (GCls). Outcomes were coronary artery calcium score (CACS) $>0$ and CACS $>400$. Differences in prevalences were assessed by odds ratios (OR). Outcomes were adjusted for cardiovascular risk factors and comorbidities.

Results: A total of $337(0.9 \%)$ patients with RA were identified. OR for having CACS $>0$ was $1.17(0.91-1.50)$ for overall RA and 1.33 (1.001.77) for seropositive RA. Patients who had received $\geq 1 \mathrm{GCl}$ in the period 3 years prior to the CCT had an OR of $1.49(0.99-2.27)$ for having CACS > $>$. The OR for having CACS > 400 was 1.31 (0.95-1.81) for overall RA and $1.49(1.04-2.12)$ for seropositive RA. OR for having CACS > 400 was $1.43(0.99-2.07)$ for RA patients treated with conventional synthetic DMARDs, but $1.01(0.51-1.99)$ for patients treated with biological DMARDs.

Conclusion: Coronary artery calcifications are more frequent in RA patients being seropositive or needing flare treatment. The occurrence of severe calcification is more frequent in seropositive RA patients and in RA patients not escalated to biological DMARDs. These findings support the hypothesis that systemic inflammation accelerates the atherosclerotic process leading to increased coronary artery calcium, which may explain the increased risk of cardiovascular events among RA patients.

Disclosure of Interests: None declared

DOI: 10.1136/annrheumdis-2019-eular.2551 